\title{
Knowledge, Attitude and Practices Regarding "Reverse Quarantine" during COVID 19 Pandemic among Senior Citizens in an Urban Area of Kerala - A Longitudinal Study
}

\author{
Meera Karunakaran ${ }^{1}$, Jayasree Chandrasekharan Nair Saradamma² \\ 1, 2Department of Community Medicine, Travancore Medical College, Kollam, Kerala.
}

\section{ABSTRACT}

\section{BACKGROUND}

Elderly people especially those with co-morbidities are considered to be more at risk to suffer from serious infection and complications due to corona virus disease 19 (COVID 19) infection. The concept of reverse quarantine which ensured minimum contact of vulnerable individuals with others was put forward even from early days of the pandemic. How much the vulnerable individuals were aware of the concept, its practice and the apparent outcome is of interest. This information could be used in designing infection prevention measures.The purpose of this study was to determine the knowledge, attitude \& practice regarding "reverse quarantine" among senior citizens.

\section{METHODS}

A longitudinal study was conducted in the urban area of Kollam district in Kerala from June $1^{\text {st }} 2020$ to May 31 2021 (1 year). The study subjects included 128 individuals above 60 years, residing in the area.

\section{RESULTS}

Majority of study subjects had good knowledge and the right attitude regarding reverse quarantine. Regarding correct practices, $70 \%$ of them were following good practices on reverse quarantine. None of them received any assistance from health care providers in ensuring reverse quarantine.

\section{CONCLUSIONS}

Improving the practice of reverse quarantine will bring about further protection of vulnerable groups, even after being fully vaccinated.

\section{KEY WORDS}

COVID - 19, Risk - Group, Senior Citizens, Self-Protection, Reverse Quarantine.

\author{
Corresponding Author: \\ Dr. Jayasree Chandrasekharan Nair \\ Saradamma, \\ Sreeramgam, A-4, Sreeramgam Lane, \\ Sasthamangalam, Thiruvananthapuram, \\ Kerala, India. \\ E-mail:jayasree_cs@yahoo.com
}

DOI: $10.14260 /$ jemds $/ 2021 / 792$

How to Cite This Article:

Karunakaran $M$, Saradamma JCN. Knowledge, attitude and practices regarding "reverse quarantine" during Covid 19 pandemic among senior citizens in an urban area of Kerala - a longitudinal study. J Evolution Med Dent Sci 2021;10(45):3920-3924, DOI: 10.14260/jemds/2021/792

Submission 10-11-2021,

Peer Review 08-12-2021,

Acceptance 14-12-2021,

Published 28-12-2021.

Copyright (C) 2021 Meera Karunakaran et al. This is an open access article distributed under Creative Commons Attribution License [Attribution 4.0 International (CC $B Y$ 4.0)] 


\section{BACKGROUND}

The world is witnessing today one of the worst public health emergencies in recent times. The report of a cluster of pneumonia cases from Wuhan, Hubei province in China in December 2019 heralded the onset of the pandemic that is wrecking across the world now. Corona viruses are a family of respiratory viruses, named for the crown-like spikes on their surface. They are notorious to mutate quickly and acquire new qualities. Commonly, people get infected with human corona viruses 229E, NL63, OC43, and HKU1. Coronaviruses can cause diseases ranging from the common cold to life threatening pneumonitis/ lower respiratory tract infection (LRTI) especially in vulnerable population. ${ }^{1}$

The novel corona virus outbreak (2019-nCov) was declared by the World Health Organization as a public health emergency of international concern (PHEIC) on 21 st January 2020. Concerned by the spread, severity and alarming levels of infection, the WHO made an assessment that COVID19 can be characterized as a pandemic. ${ }^{2}$

The causative organism has been identified and named as severe acute respiratory syndrome corona virus2 (SARS Cov2) on $11^{\text {th }}$ February 2020 by the international committee on taxonomy of viruses. The mode of transmission is considered to be via the respiratory route, mainly by droplet infection. The symptoms may appear $2-14$ days after exposure and may vary in severity. Symptoms include mainly fever, cough with a few having difficulty in breathing or diarrhea. Chest radiographs may show invasive pneumonic infiltrates in both lungs. Severe acute respiratory syndrome, kidney failure or death can occur. On the basis of a case definition requiring a diagnosis of pneumonia, the currently reported case fatality rate is approximately $1.4 \%$ to $2 \%$ amongst patients with wide spectrum of disease severity. This suggests that the overall clinical consequences of COVID19 may ultimately be more similar to that of a severe seasonal influenza (which has a case fatality rate of approximately $0.1 \%$ ) and not like that of a disease similar to SARS or middle east respiratory syndrome (MERS), with case fatality rates of 9 to $10 \%$ and $36 \%$, respectively. ${ }^{3}$

No curative treatment is available. Even fully vaccinated individuals are found to contract the disease even if in a milder form. Based on currently available scientific data, prevention of spread of COVID 19 is considered to be possible through three main measures - using an effective mask, maintaining a distance of at least 6 feet from other individuals and using sanitizer/soap \& water to disinfect the hands frequently. ${ }^{3}$

The additional precautions laid down include

1. Follow the culture of 'Namaste'

2. Follow respiratory hygiene / cough etiquette (see above)

3. Maintain safe food practices, i.e eat well-cooked food which has been prepared hygienically

4. Avoid travel, especially international travel unless really necessary.

In addition to these measures, "reverse quarantine" of atrisk individuals is also considered effective. Reverse quarantine aims at keeping individuals who are vulnerable and capable of developing severe disease/death, away from the general public. The vulnerable individuals includes elderly, people with diabetes, hypertension, lung disease, kidney disease, and immunocompromised people. ${ }^{3}$

The elderly constitute $16.5 \%$ of the total population of Kerala. This is the highest proportion among all the Indian states. ${ }^{4}$ Their age and the morbidities found commonly in that group make them a high-risk category as far as COVID 19 infection is concerned. ${ }^{5}$ The disease tends to be more severe in these individuals. Complications are more. So, we were interested in finding out the awareness of the senior citizens regarding the prevention measures, especially reverse quarantine, and to what extent they are able to practice the quarantine measures.

\section{Objective}

To determine the knowledge, attitude and practices regarding 'reverse quarantine' during COVID 19 pandemic among senior citizens of an urban area of south Kerala.

\section{METHODS}

This longitudinal study was conducted in an urban area in Kollam district of Kerala from 1st June 2020 to 31 ${ }^{\text {st }}$ May 2021. The sample size included adults above 60 years who are residents of the study area for the previous one year. Out of the 55 municipal wards, 12 come under the field practice area of Travancore Medical College, Kollam. Out of that, 4 wards were selected randomly for the study.

\section{Sample Size}

A pilot study was conducted by the investigators in among 20 households located near the hospital. Practice of reverse quarantine by elderly population was found out as $44 \%$. Based on this, the sample size was calculated as 128 , using the formula: $4 \mathrm{pq} / \mathrm{d} 2$.

\section{Sampling Technique}

32 individuals had to be selected from each ward. As this is an urban area, associations are active in all the places. The residents association functioning in each of these wards were contacted. Since it is a pandemic situation, direct collection of data by visiting households was not possible. So, the contact numbers of all the houses with residents above 60 years of age were collected from the resident's address directories. This was done for all the four selected wards and lists were prepared. Then 32 houses were selected randomly from each of these four wards. If no response was got, the immediate next contact number was reached and data collection was done by the investigator over phone.

\section{Inclusion Criteria}

- $\quad$ Persons aged 60 years or more

- Resident of the area for at least past 1 year 


\section{Exclusion Criteria}

- Not willing to participate in the study.

- People having issues with hearing, speech, seriously ill persons, mentally challenged individuals.

\section{Data Collection}

The subjects were contacted over phone and were interviewed by using a pre tested structured questionnaire. They were followed up over phone every 3 months for a period of 1 year.

Follow up was done to find out whether anyone in the study grouo developed COVID - 19 during the 1 year period.

All the participants got 2 doses of Covishield vaccine also during the 1 year period.

2 of the participants developed COVID 19 in 1 year period. This was before they got any dose of the vaccine.

1 of them died. That individual had multiple comorbidities.

All the participants got 2 doses of Covishield vaccine also during the 1 year period.

\section{Statistical Analysis}

Data entry was done in Microsoft Excel. Analysis was done using Statistical Package for Social Sciences (SPSS). Frequencies \& percentages were calculated. Significance test was done by using Chi square test. A p value of $<0.05$ was considered significant.

For assessing the knowledge, attitude and practice score, correct response to at least $80 \%$ of the questions was considered as "good", correct response to at least $50 \%$ of the questions was considered "moderate" and correct response to less than $50 \%$ questions was considered "poor".

Due clearance from the Institutional Ethical Committee (IEC) was obtained and after taking informed consent from the subjects, the study was conducted.

\section{RESULTS}

In this study, most (60\%) of the subjects belonged to the 70 79 age group. $55 \%$ were graduates. Majority (70 \%). 80.4\% had one or more morbidities. 5 persons (4\%) were bed ridden individuals.

$21 \%$ of the subjects failed to take regular medications even when $98.3 \%$ claim to have had no difficulty in accessing the drugs. As far as ailments are concerned, $65.5 \%$ never had to visit a doctor during the 1-year study period.

\begin{tabular}{|ccc|}
\hline Variable & Frequency & Percentage \\
Age Distribution & & \\
$60-69$ & 20 & 15 \\
$70-79$ & 76 & 60 \\
80 and above & 32 & 25 \\
Gender Distribution & & \\
Male & 49 & 37.9 \\
Female & 79 & 62.1 \\
Marital Status & & \\
Married & 128 & 77.4 \\
Widowed & 29 & 22.6 \\
Educational Status & & \\
Illiterate & 9 & 7 \\
Primary & 33 & 26 \\
Secondary & 18 & 14 \\
Higher secondary & 13 & 10 \\
Graduate & 55 & 43 \\
\hline
\end{tabular}

\begin{tabular}{|c|c|c|}
\hline Occupational Status & & \\
\hline Never employed & 96 & 75 \\
\hline Previously working \& retired now & 32 & 25 \\
\hline Ration card & & \\
\hline White & 73 & 56.9 \\
\hline Blue & 35 & 27.6 \\
\hline Pink & 20 & 15.5 \\
\hline Type of Family to Which They Belong & & \\
\hline Extended & 90 & 70.9 \\
\hline Nuclear & 38 & 39.3 \\
\hline COVID Status at the Start of the Study & & \\
\hline Positive & 9 & 6.9 \\
\hline Negative & 119 & 93.1 \\
\hline Close Contact with COVID Patients & & \\
\hline No & 110 & 86.2 \\
\hline Yes & 18 & 13.8 \\
\hline Co-morbidities among the Participant & & \\
\hline With no co-morbidity & & \\
\hline With one co-morbidity & $\begin{array}{l}12 \\
44\end{array}$ & $\begin{array}{l}19.6 \\
34.4\end{array}$ \\
\hline With multiple co-morbidities & $\begin{array}{l}44 \\
72\end{array}$ & $\begin{array}{c}34.4 \\
56\end{array}$ \\
\hline Mobility of Participants & & \\
\hline Bed ridden & 5 & 4 \\
\hline Needs help to move inside the house & 12 & 9 \\
\hline Needs help to move outside the house & 28 & 21.6 \\
\hline Totally independent & 83 & 65.4 \\
\hline Total & 128 & 100 \\
\hline Table 1. Sociodemographic Charac & stics of the Stu & y Population \\
\hline Variable & Frequer & cy Percentag \\
\hline Having Regular Medications & & \\
\hline Yes & 101 & 79 \\
\hline No & 27 & 21 \\
\hline Any Problem in Getting Medicatio & & \\
\hline Yes & 2 & 1.7 \\
\hline No & 126 & 98.3 \\
\hline Any Problem in Getting Treatmen & & \\
\hline Yes & 8 & 6.4 \\
\hline No & 120 & 93.6 \\
\hline Need for Hospitalization in the Past $6 \mathrm{~N}$ & & \\
\hline Yes & 31 & 24.1 \\
\hline No & 97 & 75.9 \\
\hline Need to Visit a Doctor for Minor Ailmen & & \\
\hline Previous 6 Months & 44 & 34.5 \\
\hline Yes & 84 & 65.5 \\
\hline No & 84 & \\
\hline Number of Visits to the Doctor & & \\
\hline Never visited & 84 & 65.5 \\
\hline Visited once & 28 & 22 \\
\hline Visited more than once & 16 & 12.5 \\
\hline Total & 128 & 100 \\
\hline Table 2. Health Care Needs of Study & icipants durin & the Pandemic \\
\hline Variable & Frequency & Percentage \\
\hline Place of Reverse Quarantine & & \\
\hline Home & 126 & 98.3 \\
\hline Old age care institution & 2 & 1.7 \\
\hline Number of Members in the House Hold & & \\
\hline 1 & 2 & 1.7 \\
\hline 2 & 26 & 20.7 \\
\hline 3 & 22 & 17.2 \\
\hline 4 & 31 & 24.1 \\
\hline 5 or more & 47 & 36.3 \\
\hline Separate Room & & \\
\hline Yes & 113 & 87.9 \\
\hline No & 15 & 12.1 \\
\hline Separate Bathroom & & \\
\hline Yes & 102 & 79.3 \\
\hline No & 26 & 20.7 \\
\hline Care Taker Present & & \\
\hline Yes & 53 & \\
\hline No & 75 & \\
\hline Assistance from Health Care Providers & & \\
\hline No & 128 & 100 \\
\hline Yes & 0 & 0 \\
\hline Total & 128 & 100 \\
\hline
\end{tabular}

For $98.3 \%$ subjects, the place of reverse quarantine was their home itself. Majority had the facility of a separate room and bathroom. Care taker was available for $41.4 \%$ of the subjects. Interestingly, none of them reported of any assistance from health care providers during their reverse quarantine. 


\begin{tabular}{|ccc|}
\hline Variable & Frequency & Percentage \\
Feeling lonely/sad & & \\
No & 82 & 63.8 \\
Yes & 57 & 36.2 \\
Feeling social isolation & 71 & 55.2 \\
No & 57 & 44.8 \\
Yes & $\mathbf{1 2 8}$ & $\mathbf{1 0 0}$ \\
Total & & \\
\hline Table 4. Mental Issues during Reverse Quarantine \\
\hline
\end{tabular}

$63.8 \%$ reported feeling sad and $44.8 \%$ felt socially isolated.

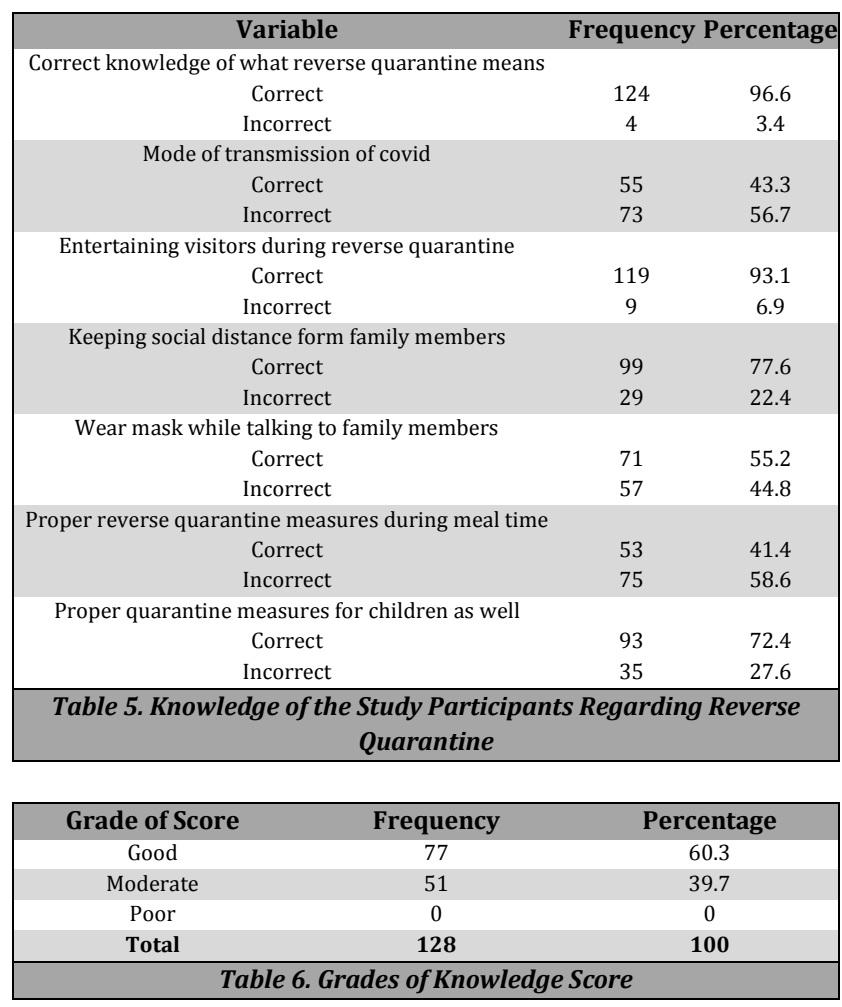

$60.3 \%$ of the participants showed good knowledge regarding reverse quarantine measures.

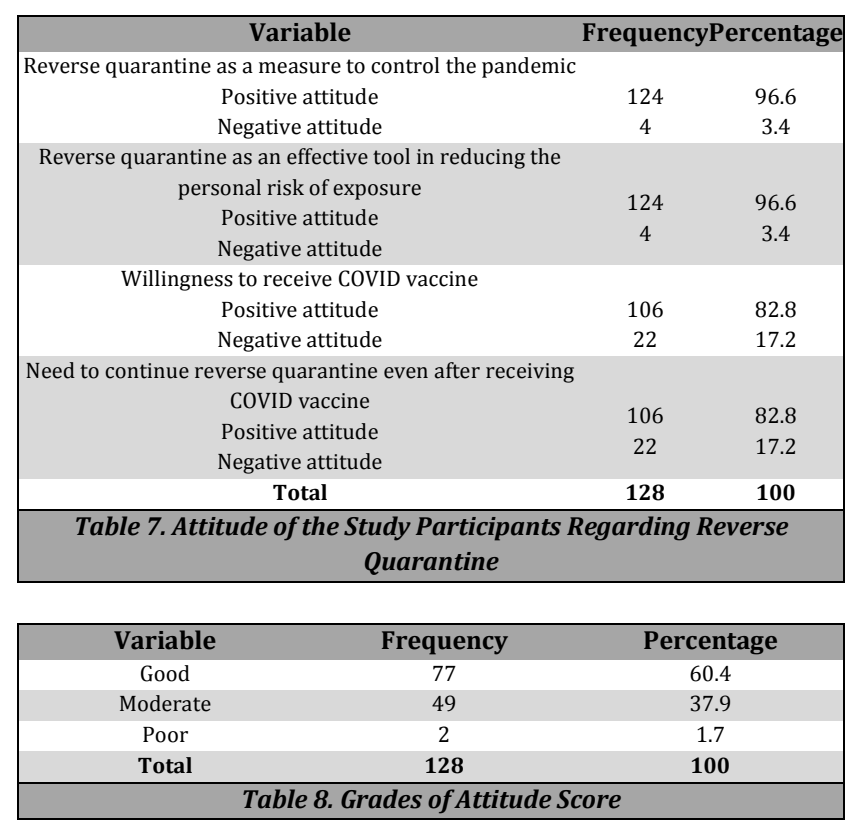

The attitude to reverse quarantine measures was right in the case of $60.3 \%$ of the participants.

\begin{tabular}{|c|c|c|}
\hline Variable & Frequency & $\%$ \\
\hline \multicolumn{3}{|c|}{ Any contact with family members who go out frequently } \\
\hline 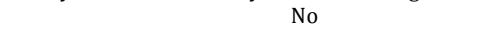 & 46 & 36.2 \\
\hline Yes & 82 & 63.8 \\
\hline \multicolumn{3}{|c|}{ Social distancing with family members who go out frequently } \\
\hline Always & 57 & 44.8 \\
\hline Mostly & 33 & 25.9 \\
\hline Sometimes & 22 & 17.2 \\
\hline Never & 16 & 16 \\
\hline \multicolumn{3}{|l|}{ Social distancing with outsiders } \\
\hline Always & 90 & 70.5 \\
\hline Mostly & 38 & 29.5 \\
\hline \multicolumn{3}{|c|}{$\begin{array}{l}\text { Wearing mask while coming into contact with family members } \\
\text { who go out frequently }\end{array}$} \\
\hline Always & 57 & \\
\hline Mostly & 33 & $\begin{array}{l}44.8 \\
250\end{array}$ \\
\hline Sometimes & 22 & \\
\hline Never & 16 & \\
\hline \multicolumn{3}{|c|}{ Wearing mask while coming into contact with outsiders } \\
\hline Always & 90 & 70.5 \\
\hline Mostly & 38 & 29.5 \\
\hline \multicolumn{3}{|c|}{ Frequent use of sanitizers/washing hands with soap \& water } \\
\hline Always & 68 & 53.4 \\
\hline Mostly & 40 & 31 \\
\hline Sometimes & 16 & 12.1 \\
\hline Never & 4 & 3.4 \\
\hline \multicolumn{3}{|c|}{$\begin{array}{l}\text { Table 9. Practices of the Study Population Regarding Reverse } \\
\text { Quarantine }\end{array}$} \\
\hline Frequency & \multicolumn{2}{|l|}{ Percentage } \\
\hline Good & \multicolumn{2}{|l|}{70} \\
\hline Moderate & \multicolumn{2}{|l|}{20.2} \\
\hline Poor & \multicolumn{2}{|l|}{9.8} \\
\hline Total & \multicolumn{2}{|l|}{100} \\
\hline \multicolumn{3}{|c|}{ Table 10. Grades of Practice Score } \\
\hline
\end{tabular}

A larger proportion of participants were following the correct practices regarding reverse quarantine $(70 \%)$ when compared to the proportion having correct knowledge and correct attitude.

All the subjects were vaccinated with 2 doses of Covishied vaccine during the period of I year follow up.

2 subjects out of 128 (1.6\%) developed COVID infection during the study period of 1 year. This was after they received both the doses of vaccine.

One person who had multiple co-morbidities, died of the infection. The other person suffered from a mild infection of COVID 19.

\section{DISCUSSION}

Our study found out that only $79 \%$ were taking medicines for their co-morbidities, even though $98.3 \%$ claimed to have faced no difficulty in accessing essential medicines. In a study on the elderly done in Singapore by Cong Ling Teo, Miao Li Chee et al. ${ }^{6} 88.6 \%$ of the participants had taken their medications regularly during the pandemic period.

Majority of the participants in our study had a separate room and bath room and $41.4 \%$ had a care -giver. In a study conducted by M. Q. Al Sabbagh et al. in Jordan, only $52.4 \%$ of the participants could afford to have a separate room and bath room. Care giver was available for $56 \% .^{7}$

We observed an interesting fact in our study. None of the participants reported as getting help from any health care personnel during their period of reverse quarantine in their homes. On the other hand, a study done by Sulaiman K. M, Muhammed Rishad et al. in Kerala, they found that $96 \%$ of the elderly people in reverse quarantine received adequate help and guidance from the health care personnel. ${ }^{8}$

Even when the physical necessities were met, a considerable degree of mental anguish and unhappiness were experienced by the subjects. In our study, $63.8 \%$ reported 
feeling sad. $44.5 \%$ felt socially isolated. Similarly, a study done in Italy by Rodolfo Rossi et al. found out that $53.1 \%$ suffered from a feeling of sadness and $31.7 \%$ felt socially isolated. ${ }^{9}$

In our study, we have included components like mode of transmission of COVID 19, social distancing, contact with many persons, wearing masks inside their homes, measures with children in the house, meal time measures in assessing their knowledge. $60.3 \%$ of the study participants expressed correct knowledge regarding various aspects of the disease. This is impressive, considering the fact that all our study participants are senior citizens.

In a study conducted by A. V Rajendran Jayadevan et al. it was noticed that the attitude score of the study group turned out to be moderately desirable in $70 \%$ of the participants. ${ }^{10}$ The study was conducted in rural North Kerala. In our study, $60.3 \%$ scored good with regards their attitude regarding COVID 19 prevention measures. Since our study was conducted in an urban area, it can be assumed that, this better score is due to the better exposure of the individuals in this area to information. ${ }^{11}$

As regards practice, $70 \%$ of the participants are practicing the correct measures of prevention. It is interesting to note that even though their knowledge and attitude regarding prevention measures is good only in 60.3 $\%$ of the subjects, $70 \%$ is practicing the prevention measures in the required manner. This is to be appreciated, as all our participants are senior citizens who are vulnerable to get severe COVID 19 infection and complications. Studies conducted by Zhonggen Sun, Binquing Yan et al. in elderly Chinese population agrees with our findings. ${ }^{12}$ The high compliance with correct practices by the elderly was observed in other studies like those conducted by Cao, Y, Zhang et al. in China and Chai $\mathrm{H} \mathrm{C}$ et al. in Melbourne, Australia underlines this finding especially with the urban elderly.13,14

\section{CONCLUSIONS}

$60.3 \%$ of senior citizens had good knowledge and exhibit correct attitude towards preventive measures. It is interesting to note that $70.3 \%$ follow correct practices of prevention measures. This could be improved to $100 \%$ by enhanced application of appropriate IEC measures.

The involvement of health care workers was found to be meagre during the reverse quarantine period. This problem has to be given consideration when more and more people are quarantined.
Data sharing statement provided by the authors is available with the full text of this article at jemds.com.

Financial or other competing interests: None.

Disclosure forms provided by the authors are available with the full text of this article at jemds.com.

\section{REFERENCES}

[1] https://dashboard.kerala.gov.in>covid Last accessed on $11-10-2021$

[2] Covid-19.who int - Last accessed on 11-10-2021

[3] Burbudde SB, Racood DB, Gaonkar PP, et al.Global scenario, public health concerns and mitigation strategies to counter current ongoing SARS-CoV-2 / COVID-19 pandemic. Hum Vaccine Immunother 2020;16(12):3023-33.

[4] http://prsindia.org>policy>national - family - health survey - Last accessed on 23 - 10 -2021

[5] Gulia KK, Kumar VM. Reverse quarantine: management of Covid - 19 by Kerala with its higher number of aged population.Psychogeriatrics 2020;10.1111/psyg.12582.

[6] http://www.nature.com/scientific reports. Last accessed on4-11-2021

[7] Mohammed Qussay Al Sabba. hhttp://orcid.org/00000002-4872-7116.Last accessed on 4 -11 -2021

[8] https://lldoi.org/10.1101/2020.06.15.2013208.Last accessed on 23-11-2021

[9] Rossi R, Socci V, Talevi D, et al.Covid-19 pandemic and lockdown measures - impact on mental health among the general population in Italy. Front Psychiatry 2020;11:790.

[10] Raveendran AV,Jayadevan R. Reverse quarantine and COVID-19. Diabetes and Metabolic syndrome: Clinical Research and Reviews 2020;14(5):1323-25.

[11] Nussbaumer-Streit B, Mayr V, Dobrescu AI Quarantine Alone or in Combination with other Public health measures to control Covid-19-a rapid review.Cochrane Database Syst Rev 2020;4(4):CD013574.

[12] Sun Z, Yang B, Zhang R, et al. Influencing factors of understanding Covid - 19 risks and coping behaviour among the elderly population. Int J Environ Res Public Health 2020;17(16):5889.

[13] Cao Y, Zhang HZ.Investigation on disease cognition and coping attitude and influencing factors of elderly persons. Chin Gen Pract Nurse 2019(17):1117-9.

[14] Chai HC. Research on social practices and influencing factors among urban retired elders. Master's thesis, Shandong University, Jinan China 2013. 